said enough to show that if all the medical schools would abolish compulsory tests, the results of our mode of teaching would compare favourably with any other school in the country, and entitle us to rank as the nucleus of a medical faculty in a university.

I will not now discuss the question whether it is possible at the present day to establish a new university in England which should ignore the claims of such an important academic study as medicine. I will only say that until the one-portal system of licensing to practise--a system which we shall all welcome-has been established, we simply ask for equal rights with other universities in this direction. I am, Sir, your obedient servant,

EDward Lund, F.R.C.S. Manchester, July 26th, 1879. Prof. of Surgery in the Owens College.

* * We shall revert to one phase of this question in an early number.-ED. L.

\section{SALICIN AND SALICYLIC ACID.}

\section{To the Editor of THE LANCET.}

SIR,-Dr. Senator ${ }^{1}$ has misunderstood my position, and I am glad that he has given me the opportunity to explain this more fully.

I was quite aware that the idea that salicin is converted into salicylic acid did not originate with him, and ought, perhaps, to have said so. But the point to which I wished to direct attention was not the chemical aspect of th question so much as the therapeutic, not whether or not salicin may be converted into salicylic acid, but whether or not it oues its anti-rheumatic effects to such conversion. Dr. Senator asserts that it does. That is the position with which his name is associated, and that is the position against which my remarks were directed.

The chemistry of the salicyl compounds is far from being thoroughly understood. There are altogether some thirty or forty of them. Regarding the nature of the changes which they undergo out of the system, we have really very little definite and reliable knowledge. Under these circumstances it seems to me rash to decide so unhesitatingly as Dr. Senator has done on the nature of the changes which any one of them undergoes in the system. It is very difficult to say exactly what change any drug undergoes in its passage through the system. It is still more so in the case of one having such complex relationships as salicin.

But the chief question is the therapeutic one. Does salicin owe its anti-rheumatic effect to its conversion into salicylic acid? The discussion of this point presupposes the admission that it may be so converted, and, for argument's sake, I will grant that it is so. The question immediately arises, Where does this change take place? Is it in the digestive organs? Is it in the circulation? Does it take place all over the body, or is it only in the eliminating organs? If in the digestive organs, the whole would be taken at once into the system as salicylic acid, and no difference would be noted between the effects of the two drugs. It cannot well be there. If in the circulation, the same thing would happen; the mass of the blood would be adequate to change thirty grains of salicin into salicylic acid as quickly as ten. It is not likely there. If in the tissues generally, its conversion would be equally rapid. There is nothing to prevent them converting at once into salicylic acid any quantity of salicin which is ever administered; it is evidently not there that the slow and gradual conversion of salicin into salicylic acid takes place. There remain only the eliminating organs. There its conversion might possibly be slow, and even partial ; but, as I remarked in the paper which Dr. Senator criticises, the salicin has exercised its full therapeutic effect before it has reached the stage of elimination, and before it has undergone the changes which immediately precede it.

There is no $\dot{a}$ priori reason why the conversion of salicin into salicylic acid should be slow and gradual, unless the change take place in the eliminating organs after its therapentic effects have been produced. If salicin is converted into salicylic acid before its anti-rheumatic effects have been

1 The LaNCET, July 19th. produced, such conversion is more likely to be rapid than slow, and Dr. Senator has himself given as an instance of the rapidity of its conversion the fact that from fifteen to twenty minutes after taking thirty grains of salicin his urine gave a marked blue reaction with perchloride of iron. Here I would stay to remark that other salicyl compounds besides salicylic and salicyluric acids give the same reaction. It is therefore no proof that either of these exists in the urine. In my experience, a pretty large one, salicin acts as rapidly as salicylic acid, which it would not do if it owed its action to its slow conversion into that acid. The cases in which I prefer salicylate of soda are those in which the administration of an alkali is indicated, as it generally is in those who have suffered frequently.

Slow conversion means, not that the chemical change is long in taking place, but that, as Dr. Senator says, "only a part of the salicin is converted into salicylic acid." But if that were the case, fifteen grains should be as efficacious a dose as thirty. If, when fifteen grains are given, only twelve are in a given time converted into salicylic acid, no more than twelve would in the same time be so converted if we were to give thirty, and twelve grains would be as efficacious a dose as thirty. But that is in direct opposition to clinical experience. It is a fact that thirty grains of salicin every hour cure a case of acute rheumatism more quickly than thirty grains every two hours; showing that within two hours (if Dr. Senator's view is correct) more than thirty, and probably sixty, grains have been converted into salicylic acid. That is not slow and gradual conversion.

Yet one more fact. In some cases salicylic acid produces great disturbance of the nervous centres, as indicated by depression and delirium, often great and alarming. While the patient is suffering from these symptoms-while he is still under the influence of the salicylic acid-salicin may be given freely, and under (though, of course, not in consequence of) its use, the alarming symptoms disappear. While depressed or delirious from salicylic acid, a man may take from twenty to thirty grains of salicin every hour with nothing but benefit. That the salicin is taken in sufficient dose is proved by its rapidly curing the rheumatism; that it does not owe its action to its conversion into salicylic acid is evidenced by the coincident disappearance of the symptoms due to that drug.

Dr. Senator's reference to the different effects of small and large doses of quinine is beside the mark. There is no question of quinine owing its therapeutic effects to its conversion into any other agency. If he only meant to say that drugs act differently in different doses, there was no occasion to say it at all, for that is generally acknowledged.

In his concluding paragraph Dr. Senator points out what he calls " a fatal error, and a contradiction in my deduetions." If he will read these paragraphs again he will see that the error is his rather than mine. His error consists in treating as my deliberate opinion what $I$ refer to as a mere hypothesis. It is quite possible that both salicin and salicylic acid may be converted into, and eliminated as, some third substance, and there is some evidence to show that both are eliminated as salicyluric acid; but when I say that I still confine myself to hypothesis, and do not give it as my opinion that such is the case. But even if $I$ held that view I should not be a convert to Senator's opinion, that salicin owes its anti-rheumatic effect to its being converted into salicylic acid in the system. Granting that such conversion does take place, the therapeutic evidence all favours the view that it occurs only after the salicin has exercised its full anti-rheumatic action.

On one other point I would again insist. Wemust draw a distinction between the action of the salicyl compounds on the rheumatic poison, and their action on the system. In my original paper on salicin (LANCET, March, 1876) I explained that I was led to use the drug because I regarded the rheumatic poison as a miasm introduced into the system from without, and which was likely to be destroyed by such an agent as salicin. The employment of salicin in acute rheumatism was not a haphazard experiment, but a legitimate deduction from the views which I held regarding the causation of acute rheumatism. The success of the practice is evidence in favour of the theory on which it is founded. The rheumatic poison I believe to be a miasm. There is no reason why the dif ferent salicyl compounds should not all exercise the same destructive effect on this miasm, and yet have different effects on the system. A priori this is quite possible. What evidence we have supports the view that it is so.

I hope I have made my position clear to Professor Senator. 
If I have, he will see that my knowledge, though imperfect enough, is not so imperfect as he thought; and that my deductions, though possibly erroneous, are not contradictory.

The whole question is too young for anything like dogmatic assertion. I do not say that my views are correct. I give my facts, and I give my interpretation of these facts. Probably many years will elapse, and many others, more competent, share the work, before either the chemistry or the therapeutic effects of the salicyl compounds are properly understood. That many of these compounds, besides salicin and salicylic acid, will be found useful, I entertain no doubt. Your obedient servant, T. J. MACLAGAN, M.D.

Cadogan-place, Belgrave-square, July 21 .

\section{THE MURCHISON MEMORIAL. \\ To the Editor of THE LANCET.}

SIR,-Allow me to call your attention to a circular which is now being largely distributed, asking for subscriptions in aid of this memorial. It has been resolved that this shall take the form of a scholarship in clinical medicine, to be competed for alternately in London and Edinburgh.

"It is intended," I quote the circular, " that the scholarship shall be open to students of all the London medical schools, and that the Royal College of Physicians shall, if practicable, conduct the award of it in London. In Edinburgh the scholarship will be administered by the medical facnlty of the university, and be open to all its medical undergraduates."

It is to this last clause that I desire to draw your particular attention. You will observe that the scholarship, when competed for in Edinburgh, is to be reserved entirely for university students. The students of the Edinburgh School of Medicine are not only ignored, but deliberately excluded from participation in the competition; while in London the scholarship is to be open to students of all the medical schools.

The manifest injustice of this scheme led me at once to commit the circular to the waste-basket, and to resolve to have nothing whatever to do with it. But on reflection, and in justice to the students of the Extra-Academical School of Edinburgh, I think it right to address you on the subject, and on behalf of the teachers in that school to enter a protest against the narrow-minded exclusiveness which suggested the proposed scheme, so contrary to the feelings and actions of him whose memory it is desired to honour.

I can hardly allow myself to believe that this scheme can be in accordance with the wishes of the teachers of clinical medicine in the university, and that it is not a mere inad. vertence on the part of the promoters of the memorial. But it is scarcely fair that for this reason the admirers of Murchison connected with the Extra-Academical School of Medicine in Edinburgh, and many others, should be debarred from testifying their regard to Murchison by offering their mite to the formation of the memorial. For this, of course, must be the inevitable result should the plan, as now propounded, be carried ont.

If this, then, be the real state of the case, and not the deliberate and final decision of the Edinburgh committee (who, it may be noted, with two exceptions, are all professors of the medical faculty), then the matter can very easily be rectified. Let the present circular be recalled. Let a new one be issued with the required amendment-viz., that the scholarship shall be open to all medical students at the University of Edinburgh and the Edinburgh School of Medicine, and that the competition in Edinburgh shall be conducted by the professors of clinical medicine in the university, conjointly with the lecturers on clinical medicine in the Edinburgh School of Medicine.

I have been induced to trouble you with these suggestions because when the secretary to the memorial in Edinburgh had the matter brought before him, his reply was that he was afraid that it was now too late to have any alteration made in the plan. Perhaps when laid before the London committee in this public way something may yet be done. Let this be my excuse for encroaching so much upon your valuable space.

I am, Sir, your obedient servant,

Claude Muirhead,

Edinburgh, July 29th, 1579.

\section{HOUSEHOLD VENTILATION.}

\section{To the Editor of THE LANCET.}

SIR,-The influence which household ventilation must exert upon the health of a population, the slighting care and little attention which it habitually receives, have led me to write the following lines, in the hope that you may think them worthy of notice.

Cold is ventilation's greatest enemy ; and in our climate it is no easy matter to ventilate dwellings without lowering their temperature to an extent incompatible with comfort. We have in the English fireplace a compromise between a ventilator and a heat-producer ; but the compromise is, as far at least as the production of heat is concerned, a poor one, for fresh air enters the room cold, and in large proportion leaves by the chimney as soon as properly warmed. Efforts are, on this account, frequently made to prevent the ingress of pure cold air, and in default stale atmospheres, and not uncommonly sewer gas, substitute themselves.

I propose to alter this. Since the exit of air by the chimney necessitates the entry of an equal volume through other channels, I would ensure its quality by running a pipe of large diameter from the external air itself. I would warm it upon its very entrance by carrying the pipe to the back of the fireplace, expanding it there in order to increase its heat-receiving surface, passing it thence again into the room, and guarding its orifice by a tap labeled "hot." A similar pipe, communicating directly with the external atmosphere, may be made to open at the same spot, and a tap labelled "cold" affixed to its extremity. With such an apparatus we could regulate the temperature of our rooms in much the same way as the hairdresser does that of the water with which he bathes our heads; always supposing that the window fittings are tolerably close and well made; cold draughts would be avoided, and a constant supply of fresh air at the same time guaranteed.

And the plan is capable of further derelopment. A branch from the hot-air pipe may be carried to the bedroom overhead, tapped as before. At night, upon retiring to rest, the hot air may be turned off from the sitting-room, where it is no longer needed, the bedroom tap may be opened, when a volume of pure warm air will ascend into that apartmenta method of heating surely preferable to that now in vogue, of warming bedrooms by burning gas in them for some hours before bed time.

Clevedon, Somerset, July 16th, 1879. GEORGE BUdD.

\section{THE ARMY MEDICAL SERVICE. To the Editor of THE LANCET.}

SrR,-I trust that your warning will not go unheeded, and that no candidates will present themselves at the examina. tion advertised for next month; at all events, until the provisions of the new Warrant are clearly before them. I can assure them that no dependence can be placed on the promises of the War Department with reference to the Medical Service; for the rules and regulations appended to a Royal Warrant by the Secretary of State for War are of such a nature as to nullify the provisions of the Warrant, and are often read in such a way by the authorities that you find yourself deceived, totally unable to discover what you are entitled to, and called upon to perform duties outside your own department, such as Admiralty and militia work, without fee or reward. I therefore say, from many years? experience, wait and see the terms of the new Warrant, but, above all, the War Office regulations thereon.

I am, Sir, your obedient servant,

July 27 th, 1879

FRED. GOODCHILD, M.D.,

Surg.-Major, M.M.D. (retired).

\section{PARIS.}

(From our own Correspondent.)

To judge from the lists of visitors published by the AngloAmerican papers, nearly every other adult male who comes to Paris at this time of the year rejoices in the title of "Dr." Allowing that three-fourths of these are Transatlantic graduates either in dentistry or chiropody, or in some other 